\title{
ANALYSIS OF VIRTUAL REALITY TECHNOLOGY APPLICATIONS IN AGRICULTURE
}

\author{
Hailin Li \\ Institute of Electronic Technology, Information Engineering University, Zhengzhou, China, \\ 450004 \\ * Corresponding author, Address: Institute of Electronic Technology, Information \\ Engineering University, 12 Shangcheng East Road, Zhengzhou, 450004, P. R. China, \\ Tel: +86-371-63538447,Email: lihl_c@yahoo.com.cn
}

Abstract: Agricultural information technology, especially virtual reality (VR) technology, will act the important roles in agricultural modernization and realm. Computer science and IT are both playing important roles in the development of agriculture and rural areas of the world. Combining agriculture science with IT and VR, the virtual agriculture technology explored new ways of studying and applying agriculture information technology. On the basis of concept of virtual agriculture given, the composition, application range and development direction of virtual agriculture were analyzed. On basis of above mentioned, the architecture of virtual crops which is a typical application of virtual agriculture was analyzed and studied, and the model of virtual crops was modeled using plant three-dimensional rebuild technique. It can improve the applications of VR in agriculture fields and advance the process of agricultural modernization.

Keywords: VR; virtual agriculture; virtual crops; architecture; model

\section{INTRODUCTION}

Nowadays, the computer science and information technology are making the transition of Chinese agriculture from traditional agriculture to modernized agriculture, they have become the most efficient methods and tools for improving the agriculture productivity and utilization ratio of agricultural resources, and they are an important means for achieving agricultural information and modernization (Jia S G, 1999; Yang Y X et al., 1999). Agriculture virtual reality, or named virtual agriculture, which is a 
major research field, is different from traditional research methods. It can integrate the agriculture science with information technology and explore new approaches to study and apply agricultural information technology to the condition of computer auxiliary design and simulation (Jin $\mathrm{R} \mathrm{Z}$ et al., 2001; Zhu Y, 2004).

In the wake of development in computer science and virtual reality technology, the research and application of virtual agriculture, which will take great effect on agricultural production, scientific research, education, research of plant diseases and insect pests and development of new agricultural machines, are far-reaching significance strategic measures to China which is a great agricultural nation (Wang C W et al., 2000; Yang $\mathrm{GC}$, 2005). The research of virtual agriculture can promote the basic agricultural theoretical research, and in turn it can promote the development of virtual agriculture and virtual reality, then advance agricultural scientific research (Su Y, 2006; Zhang Y L et al., 2001).

\section{VIRTUAL AGRICULTURE TECHNOLOGY}

\subsection{Rationale of virtual agriculture}

(1) Computable theory of crops-environment

The rationale of virtual agriculture is the truth that the relationship between crops and environment is computable. The researchers in Nanjing Agricultural University have set up a key Chinese ministry of agriculture laboratory that can regulate and control crops' growth, they made full research and simulation on the relationship between crops and environment. The results showed that the relationship between crops and environment is computable (Wang D B et al., 2006).

(2) Virtual reality technology

VR is a high-level human-computer interface featuring immersive sense, interactivity and proposition (Wang C W et al., 2000). It makes integrated use of computer graphic science, simulation technology, multi-media technology, artificial intelligence, computer network and multi-sensors technology to simulate the human sense organs such as vision, hearing and touch, and can get people immersed in the virtual states which can interact with it by the ways of language and gestures. VR has been acknowledged as one of the most important technologies that will produce great effects on human life in the 21st century (Yang G C, 2005; Holt D A et al., 2003).

The appearance and development of VR provide many new methods of solving problems for us. At present, the international societies have got ripe results of VR research on many applications, but VR technology of 
agriculture is still a future technology which is still in an exploring stage. Happily, the appearance of virtual agriculture and the tentative ideas and explorations on virtual plants, virtual farms and virtual agricultural experiments make us notice that the VR technology certainly will be used widely and will produce renovate train of thought and new means for agriculture science study and agricultural production (Yang G C., 2005; Guo Y et al., 2001; Li Z W et al., 2005).

\subsection{Fundamental conception of virtual agriculture}

Virtual agriculture extended from virtual reality which came out in the mid-1980s. Virtual agriculture is a renovation of traditional agriculture, and a new agricultural research method which gets agriculture domain as the object of study and gets advanced technology as means. It can reduce experiment costs, shorten the research time, and raise the research efficiency that agronomists carry out agricultural research in virtual environments.

At present, there are many different definitions of virtual agriculture all over the world, such as D. A. Holt and S. T. Sonka's (Holt D A et al., 2003), Academician Sun's (Chen S B et al., 2003; Sun J L, 2000) and Professor Yang's (Yang G C, 2005) definition. Synthesizing various opinions, the author gives a definition of virtual agriculture as agricultural simulation agriculture that on the basis of information technology and VR technology, and a significant subfield of VR. It views the objects of agriculture domain as core, takes advanced information technology and VR applying to complicated agricultural production, management, teaching, scientific research, planning, resource collocation and circulation of goods with the support of high-efficient and reliable communication network. And it takes networks and computers as a platform to simulate and reappear the studied objects of each link in the agriculture and achieve the aims of interaction and visualization of studied objects and environments.

\subsection{Composition of virtual agriculture}

The virtual agriculture is one of the greatest key technologies of digital agriculture. It has vast vistas on the fields of agricultural management of production, planning and resource configuration (Wang Y M, 2003).

In a broad sense, virtual agriculture includes: virtual crops, which is used to breed new varieties of rice, corn, wheat, soybean, cotton, and so on; virtual animals, which is used to cultivate new varieties of animal byproducts and aquatic product such as pig, cattle, sheep, chicken, fish; virtual agricultural machinery manufacture, which is used to design and manufacture new energy conservational and high-efficient agricultural machinery to raise working efficiency and utilization ratio of agricultural 
devices and facilities, and to raise comprehensive utilization ratio of agricultural resources; virtual farm, which can simulate the market of agricultural products and management of production (Chen S B et al., 2003).

\section{THE FUTURE OF VIRTUAL AGRICULTURE TECHNOLOGY}

The virtual agriculture is an effective and practical technology, so it possesses good prospect of application and dissemination (Zhang $\mathrm{W} \mathrm{X}$ et al., 2006). With the uninterrupted growth and ripeness, the virtual agriculture technology certainly will get greater progress on the under aspects (Wang D B et al., 2006; Li Z W et al., 2005; Zhang W X et al., 2006; Song Y H et al., 2000; frwork.htm, 2005; Zheng Y Y et al., 2004):

(1) The development and application of intelligent agricultural expert system

On the existing basis, to study the growth mechanism models of crops, fruit trees, live stocks and fowls, and depending on the knowledge of experts in agriculture, to achieve the integration with other information technologies, and then to develop all kinds of high-efficient, practical and intelligent agricultural expert systems.

(2) The application of virtual agriculture in the digital earth

Virtual reality and visualization are the technological basis of digital earth, its basic components are digital agriculture and digital city. Virtual agriculture uses visualization and virtual reality to simulate agriculture, and to achieve digital agriculture. That is, virtual agriculture is a main form of digital agriculture, and an indispensable part to digital earth.

(3) The application of virtual agriculture in the tour of agriculture

The tour of agriculture can make rational use of rural resources, simulate the activities of picking, marketing, fishing and playing to get tourists participate, experience and enjoy agricultural production, and arouse tourists' interests of loving labor, lives and nature.

\section{AN APPLICATION CASE OF VIRTUAL AGRICULTURE-VIRTUAL CROPS}

\subsection{Virtual crops}

Virtual reality can take strong sense of reality and true experience to users, and take a new interactive concept-immersed interactive environment. Applying this technology, the many years' data of crops growth can be 
simulated as a few minutes procedure of growth. It is possible to operate, observe, test and achieve crops data in short time (Su Z B et al., 2005).

Virtual crops technology applies virtual reality to simulate the structure, procedure of growth and environment of crops in three-dimensional space. It uses data collecting system to monitor environment factors changes and crops growth trends, and to study regular patterns of crops and environment. Virtual crops system has significant value for exploring crops ideal models, optimizing growth measures of crops, constructing shapes of crops, designing gardens and teaching (Sun J L, 2000; Song Y H et al., 2000; frwork.htm, 2005).

Virtual agriculture has different architectures of different targets. The architecture of virtual crops system is showed in Fig. 1.

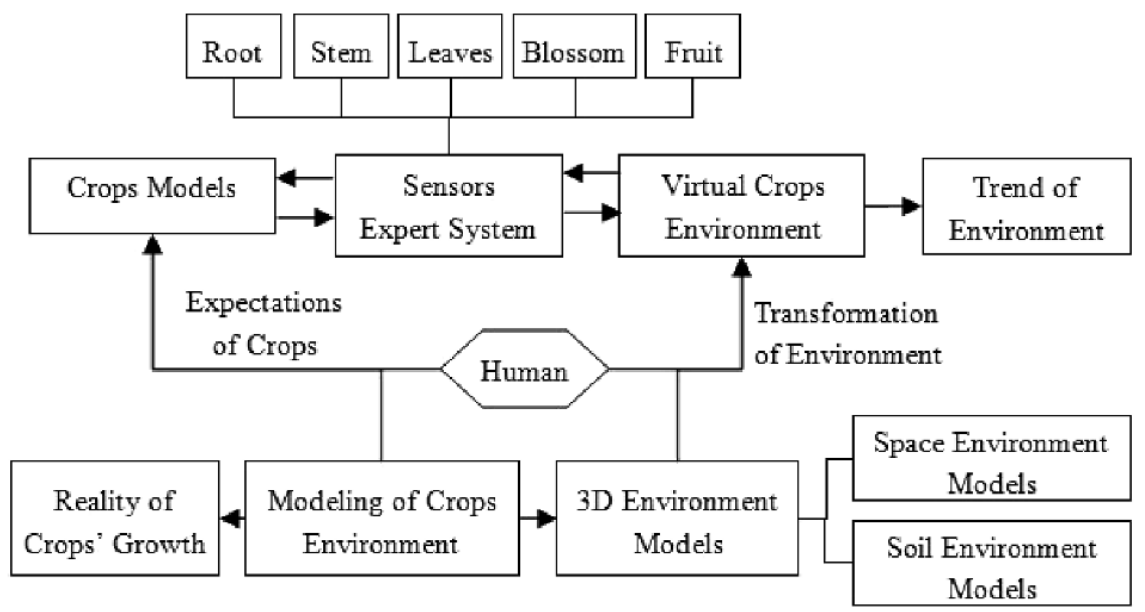

Fig. 1. The general achitecture of virtual crops system

\subsection{Research on models of virtual crops}

The models of virtual crops are built based on crops research of real world. Firstly, it should take accurate quantitative research on shapes and constructions of real crops, sum up growth law crops, then express them with proper methods ( $\mathrm{Su} \mathrm{Y,} \mathrm{2006).}$

In this paper, the three-dimensional rebuild method of plants was used to build the model. It used instruments to collect spatial data and environment data of crops, to program in computer to call the achieved data, then, to achieve the three-dimensional simulation of crops. This is a simulated method of real crops. With the improvement of instrument precision, the realness of crops simulated will be higher (Shen W J et al., 2002).

The typical component parts of crops are root, stem, seeds, leaves, blossom and fruit (frwork.htm, 2005; Su Z B et al., 2005). The root is called 
underground part, it interacts with soil environment. The stem, leaves, blossom, fruit and seeds are called ground part, it interacts with spatial environment. There are interaction and cooperation among organs of crops. The human being as an environmental factor is a intelligent agent. The human being can change parameters of related environmental factors to observe the procedure of growth and evolution of virtual crops and get the purpose of study and teaching. The fig. 2 shows the model structure of virtual crops system.

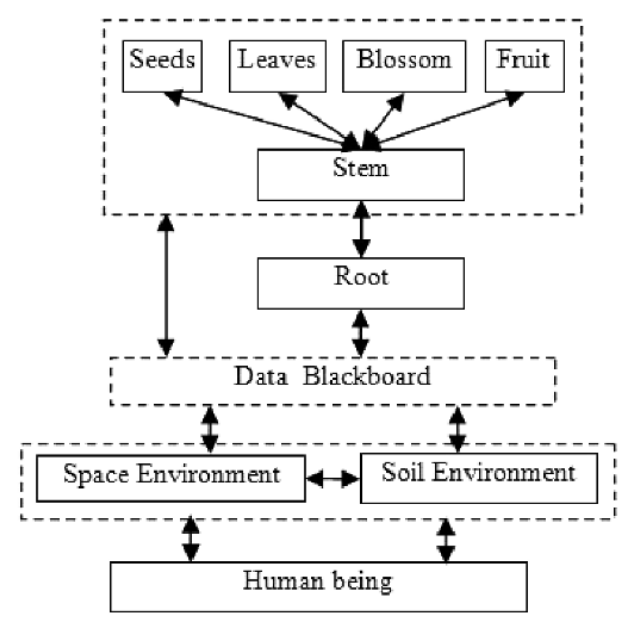

Fig. 2. Model of Virtual Crops System

\section{CONCLUSIONS}

Virtual agriculture is the result of combining agriculture science with information and virtual reality technology. It makes agronomists develop agricultural research in the virtual environment, this can reduce experiment costs, shorten the research time, get visualized process and experiment results directly, and improve the research efficiency of agricultural domain.

The applications of virtual crops have two problems to be improved and perfected: the interaction between virtual crops and environment and the virtual root system of crops. With the advances of the above problems, agricultural production will certainly produce earthshaking change in China. At the same time, the research of virtual agriculture technology has been risen as an international forward agriculture technology. 


\section{REFERENCES}

Chen Shen-bin, Sun Jiu-lin. Virtual Agriculture and Virtual Reality-Potential Application of Scientific Database. http://www.pcvr.tom.cn, 2003.

Guo Yan, Li Bao-guo. The Research Progress of Virtual Plants [J]. Science Bulletin, 2001, 4: 273-280. (in Chinese)

Holt D A, Sonka S T. Virtual Agriculture: Developing and Transferring Agricultural Technology in the 21st Century. http://www.agr.uiuc.edu/virtagl.html, 2003.

http://www.cau.edu.cn/viscs/vplant/frwork.htm, 2005 (in Chinese)

Jia Sha-gang. Agriculture Informatization and Agriculture Scientific Revolution [J]. Computer and Agriculture, 1999, 2: 3-8 (in Chinese)

Jin Run-zhao, Wang Zhao-yi. Introduction to Virtual Reality and Applications in Agriculture. Journal of Tianjin Agricultural College, 2001, 2: 27-32 (in Chinese)

Li Zhi-wen, Han Xiao-ling. Present Situation and Development Trend of VR [J]. Information Technology, 2005, 3: 94-96 (in Chinese)

Shen Wen-jun, Zhao Chun-jiang, Shen Zuo-rui, et al. Virtual Reality Technology and Its Application in Agriculture. Research of Agricultural Modernization, 2002, 5: 378-381 (in Chinese)

Song You-hong, Jia Wen-tao, Guo Yan, et al. Advances in Virtual Crops Research [J]. Computer and Agriculture, 2000, 6: 6-8 (in Chinese)

$\mathrm{Su} \mathrm{Yu}$. Study on Progress Problems of Virtual Agriculture [J]. Shanxi Agriculture Sciences, 2006, 1: 101-103 (in Chinese)

$\mathrm{Su}$ Zhongbin, Meng Fanjiang, Kang Li, et al. Virtual plant modeling based on Agent technology. Transactions of the CSAE, 2005, 8: 114-117 (in Chinese)

Sun Jiu-lin. Agriculture Information Engineering: Theory, Method and Application [J]. Engineering Science of China, 2000, 3: 89-91 (in Chinese)

Wang Cheng-wei, Gao Wen, Wang Xing-ren. The Theory, Realization and Application of Virtual Reality Technology, Qsinghua University press, 2000 (in Chinese)

Wang Dao-bo, Zhou Xiao-guo, Zhang Guang-lu. The Technology and Application of Virtual Agriculture [J]. Agriculture Network Information, 2006, 3: 16-18 (in Chinese)

Wang Yi-ming. Situation and Development of Digital Agriculture [J]. Transactions of the CSAE, 2003, supplement: 9-10 (in Chinese)

Yang Guo-Cai. Research on Architecture of Virtual Agriculture [J]. Computer Science, 2005, 3: 125-126 (in Chinese)

Yang Yong-xia, Zhu De-hai, Tan Tai-lai, et al. The Development of IT and the Application Trend of Which in Agriculture Field [J]. Computer and Agriculture, 1999, 4: 1-6 (in Chinese)

Zhang Wei-xing, Zhu De-feng, Zhao Zhi, et al. A Brief Review of Virtual Reality Technology and Virtual Agriculture [J]. Guizhou Agriculture Sciences, 2006, 2: 115-118 (in Chinese)

Zhang Yun-lan, Zheng Jiang-ping, Chen Zheng-yu. Analysis on Agricultural Information Technology Status quo and Suggestion for Development in China [J]. Journal of Zhejiang University (Agric. \& Life So1.), 2001, 2: 229-232 (in Chinese)

Zheng Yan-yan, Zhou Guo-min. VR and fruit pruning [J]. Agriculture Network Information, 2004, 8: 10-12 (in Chinese)

Zhu Yong. Effects of Information Technology in Agriculture Modernization [J]. Agriculture Modernization, 2004, 5: 43-44 (in Chinese) 